\title{
Rehabilitation of a Patient with an Immediate Complete Denture: A Case Report
}

\author{
Mohit Handa ${ }^{1}$, Pratibha Marya ${ }^{2}$ \\ ${ }^{1}$ Department of Prosthodontics, Genesis Institute of Dental Sciences and Research, Ferozepur, Punjab, India, ${ }^{2}$ Department of \\ Conservative and Endodontics, Genesis Institute of Dental Sciences and Research, Ferozepur, Punjab, India
}

Email for correspondence: dr.mohithanda@gmail.com

\begin{abstract}
The immediate complete denture is an accepted method of restoration for the patient whose last remaining teeth are to be removed. The prosthesis is fabricated before the removal of the teeth and is inserted immediately after the extractions. The purpose of the paper is to draw the attention to the need for immediate complete denture fabrication. The aims, advantages, and disadvantages of immediate dentures as well as contraindications are described in detail. The present case reports the clinical and technical steps in completing an immediate complete denture.
\end{abstract}

Key words: Immediate complete denture, interim prosthesis, rebasing

\section{INTRODUCTION}

Man has always felt the need for replacing lost teeth. Many years ago, the dental profession recognized and accepted patients' wish and need to avoid an edentulous period, which resulted in fabrication of dentures that can be placed in the patient's mouth immediately following the removal of the last natural teeth. Any removable dental prosthesis fabricated for placement immediately following the removal of natural tooth/teeth is known as immediate denture. ${ }^{[1]}$ The placement of complete denture immediately following the removal of natural teeth is not new. As early as 1860, Richardson described the use of immediate dentures. In line with the present day, immediate dentures are a necessity to prevent distress, anxiety, and embarrassment to many people. ${ }^{[2]}$

According to Rahn and Heartwell, the immediate complete denture should satisfy the following requirements: (1) Compatibility with the surrounding oral environment, (2) restoration of

\begin{tabular}{|l|l|}
\hline Quick Response Code & Article Info: \\
\hline doi: 10.5866/2018.10.10056 \\
\hline $\begin{array}{l}\text { Received: } 29-12-2017 \\
\text { Revised: } 26-01-2018 \\
\text { Accepted: 02-02-2018 } \\
\text { Available Online: 15-04-2018, 2018 (www. } \\
\text { nacd.in)@ NAD, 2018 - All rights reserved }\end{array}$ \\
\hline
\end{tabular}

masticatory efficiency within limits, (3) harmony with the functions of speech, respiration, and deglutition, (4) esthetic acceptability, and (5) preservation of the remaining hard and soft tissue support. ${ }^{[2]}$

\section{CASE REPORT}

A 52-year-old male patient reported to the department of prosthodontics complaining of missing teeth and pain in upper front tooth and wants esthetic replacement. Intraoral examination revealed Kennedy Class I Division 1 edentulism in maxillary arch and mandibular arch [Figure 1]. The patient was wearing removable partial denture in maxillary and mandibular arches and was satisfied. The remaining abutments presented advanced periodontal disease. The patient was adamant that he could not be edentulous for any length of time. The patient was having pain in 11, so extraction was done. After clinical and radiographic examination of the patient, immediate complete denture was planned.

1. Diagnostic impressions were made with irreversible hydrocolloid impression material and poured in dental stone to obtain the diagnostic cast.

2. Special trays were fabricated with autopolymerizing polymethylmethacrylate resin $2 \mathrm{~mm}$ short of all the sulci.

3. Border molding was done on maxillary and mandibular special tray in a conventional 
manner, and dual impressions were made [Figure 2] and poured into dental stone to make a master cast.

4. Denture bases were fabricated with autopolymerizing polymethylmethacrylate resin, and occlusion rims were made.

5. Jaw relation was recorded, and original vertical dimensions were maintained.

6. Teeth arrangement and try-in were done as per jaw relation [Figure 3].

7. Pocket depths were measured for each tooth from buccal, palatal, mesial, and distal sides with the help of periodontal probe.

8. The pocket depth was marked on master cast with pencil, and teeth were removed with the help of saw, trimmed with lacron carver, and smoothened with the help of sandpaper.

9. A template was fabricated for maxillary and mandibular completely edentulous ridges on the prepared master cast with clear autopolymerizing polymethylmethacrylate resin [Figure 4].

10. Teeth arrangement was done on the remaining arches.

11. After processing, finishing and polishing were done in conventional manner.

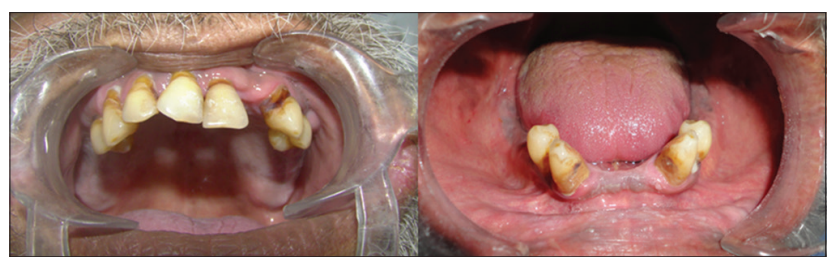

Figure 1: Intraoral picture showing Kennedy Class I Division 1 edentulism in maxillary arch and mandibular arch

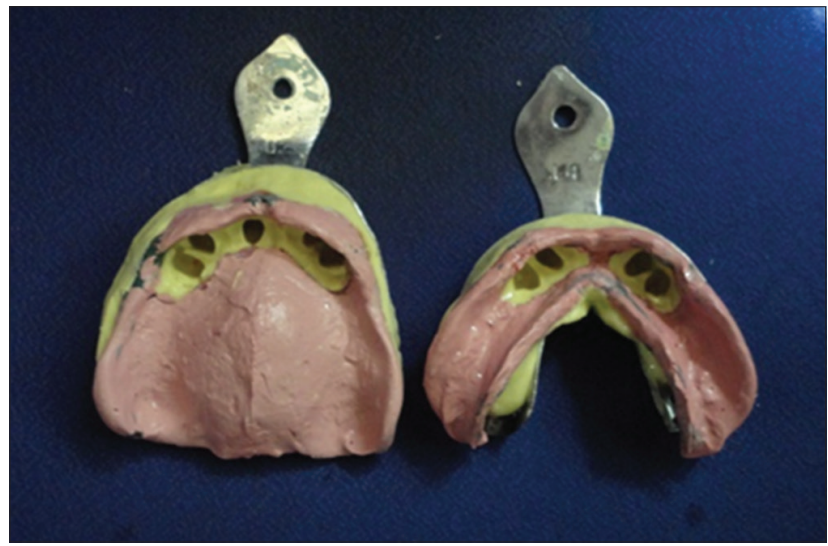

Figure 2: Dual impressions were made and poured into dental stone to make a master cast
12. Dentures were cleaned by soap and water and disinfected by immersing them in antiseptic solution for $1 \mathrm{~h}$.

13. Next day extraction was done for all the remaining teeth, and bone filing was done with the help of template and suturing was done [Figure 5].

14. Excess blood was cleaned, and immediate complete dentures were inserted in oral cavity [Figure 6].

15. Post-insertion instructions were given, and the patient was recalled after $24 \mathrm{~h}$ for follow up.

16. The patient was advised to keep the denture in the mouth for the first $24 \mathrm{~h}$ due to postextraction edema that can cause difficulty in placing the denture back in the mouth.

17. Next day, denture cleaning was done in running water and disinfection was done with antiseptic solution and inserted into patient's mouth.

\section{DISCUSSION}

Raczka and Esposito fabricated an immediate denture with the use of patient's current prosthesis and called it "Jiffy denture." Jiffy means immediate
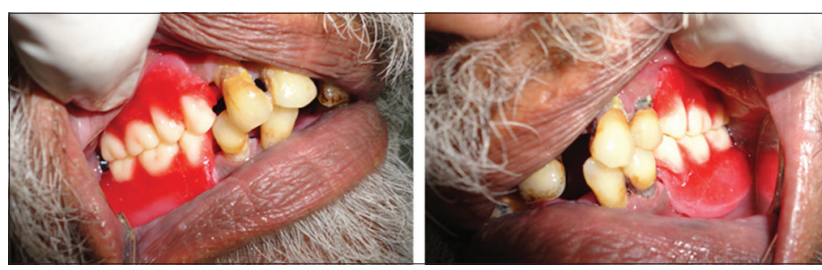

Figure 3: Teeth arrangement and try-in were done as per jaw relation

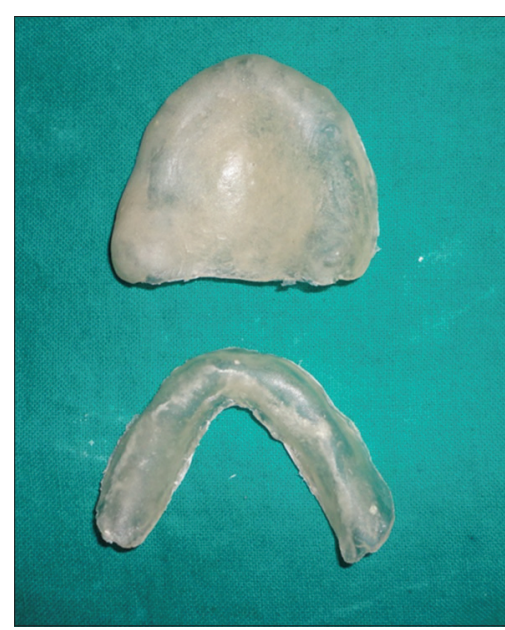

Figure 4: Fabrication of template for maxillary and mandibular completely edentulous ridges on the prepared master cast with clear autopolymerizing polymethylmethacrylate resin 


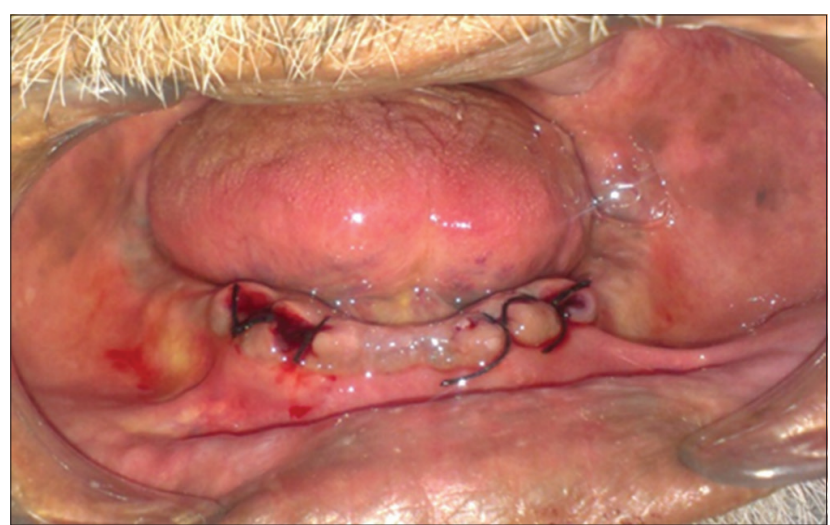

Figure 5: Extraction was done for all the remaining teeth and bone filing was done with the help of template with sutures placed

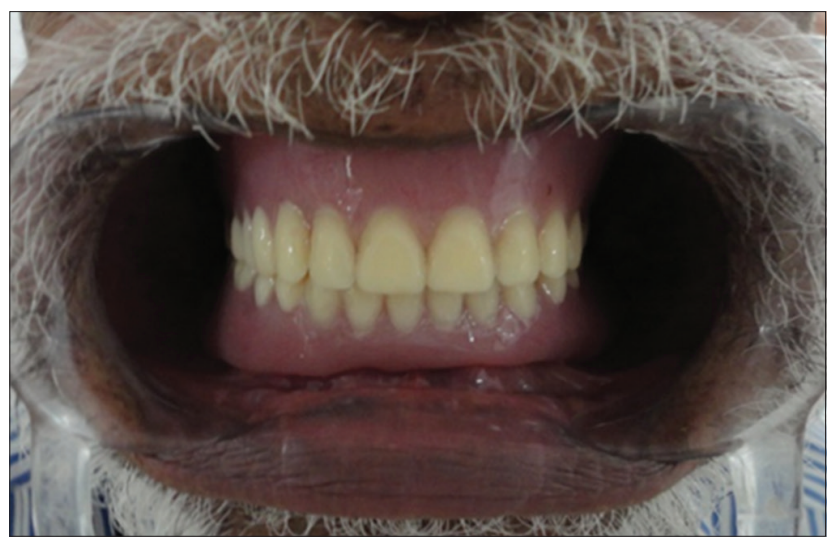

Figure 6: Insertion of immediate complete dentures in oral cavity

and quick, and Jiffy denture is a type of immediate denture that is fabricated quickly in the least time possible. Kahn and Haeberle described on appointment construction of immediate transitional complete denture using autopolymerizing acrylic resin, tooth-colored acrylic resin, and light-cured resin. Fabrication of Jiffy denture as a cost-effective technique has also been reported using a vacuumforming machine without the need for conventional laboratory techniques. ${ }^{[3]}$

Pound recommended the use of an interim prosthesis to assist the partially dentate patient in the transition to edentulism. This interim removable partial denture was designed to enhance esthetics and to provide tooth stabilization and occlusal function for a limited period of time. He recommended the use of the partial dentures until the patient was "comfortable and able to chew with force." After the remaining teeth were extracted, a definitive complete denture replaced the interim prosthesis. ${ }^{[3,4]}$ It has been suggested that "transitory" or "temporary" dentures would be more appropriate terminology for immediate dentures. These terms have merit; however, "That which by its inherent nature must sooner or later pass or end" does not define the immediate complete denture. The term "treatment denture" has been suggested, although this term seems more appropriate for a prosthesis used in diagnosis or during surgical procedures. "Temporary" could be interpreted by the patient to mean that a subsequent denture would be permanent, a situation which could present an embarrassing patient-dentist relationship at a later time. The term "temporary" could be applied to any denture since no denture should be considered to be permanent. ${ }^{[5]}$

There are some advantages and disadvantages of immediate complete denture:

Advantages of immediate denture consist of:

1. The denture acts as a bandage or splint to help control bleeding and trauma.

2. Vertical dimensions are maintained with immediate dentures.

3. Patients regain adequate function in speech, deglutition, and mastication much sooner compared to conventional complete denture.

4. With the placement of denture immediately after extraction, patients would have social life without embarrassment.

Disadvantages of immediate denture are as follows:

1. The procedures are precise and time-consuming and require more appointments, particularly during the adjustment phase.

2. The resorption is faster than the changes of healed tissue. These changes require new impressions to keep the denture base adapted to the basal seat.

3. There is no opportunity to observe the anterior teeth at the try-in appointment; therefore, the esthetic result cannot be evaluated until the dentures are inserted. ${ }^{[6,7]}$

Contraindications for immediate denture:

1. Immediate dentures are contraindicated for patients with debilitating diseases.

2. Immediate dentures are contraindicated in patients in which multiple extractions cannot be done because of systemic conditions such as 
cardiac disturbances, endocrine gland disorders, blood dyscrasias, and those with a slow healing potential.

3. Immediate dentures are contraindicated for emotionally disturbed individuals.

4. Immediate dentures are contraindicated for patients whose mental capacities do not allow them to remember post-operative instructions.

5. Immediate dentures are contraindicated for patients with acute periapical or periodontal pathosis.

6. Immediate dentures are contraindicated for patients who have extensive bone loss adjacent to the remaining teeth. ${ }^{[5,7,8]}$

The dentist should inspect intaglio surface carefully before inserting into patient's mouth. All sharp spots should be eliminated with a bur. Before it is placed in the patient's mouth, the denture is cleaned with soap and water, and it is immersed in an antiseptic solution for an hour. The patient is asked to keep the denture in the mouth for the first $24 \mathrm{~h}$ due to post-extraction edema that can cause difficulty in placing the denture back in the mouth. The patient is advised not to remove the denture for the first 3 or 4 days. Then, the denture should be taken out of the mouth for 4-8 h a day. Instructions about mouth and denture hygiene are given to the patient. ${ }^{[7,9]}$

Before the teeth are removed from the master cast, a soft pencil is used to mark the line on the gingival margin from the vestibular and oral side. If the remaining teeth have deep periodontal pockets, the depth of the pockets is measured and marked on the cast. With a small saw for plaster, mounted stone or steel bur the plaster teeth are knocked off up to the gingival margin. The teeth are eliminated one by one, and on their site, a corresponding artificial tooth is placed. The teeth which moved or changed their position should be eliminated first. If the pockets are deep, the vestibular wall can be scraped below the marked depth of the pockets, $2-3 \mathrm{~mm}$ in depth. The aim is to preserve as much bony tissue as possible. ${ }^{[7]}$
Checkup is performed at least once a year. The immediate denture is considered as permanent when it is rebased after 3-6 months. This means that, during immediate denture fabrication, it is necessary to take care of all the details in connection with retention, occlusion, esthetics, and comfort of the denture. A new denture, if necessary, is fabricated after 2 years.

\section{CONCLUSION}

An interim immediate denture can preserve the patient's appearance, muscular tone, facial height, size of the tongue, and normal speech and reduce pain following tooth extraction surgery. A need for a timely rebasing of immediate dentures and adjustment of the occlusion is also pointed out. The functional, esthetic, and psychological success of immediate dentures depends on correct indication diagnosis, treatment planning, and precisely executed fabrication procedures.

\section{REFERENCES}

1. The Glossary of Prosthodontic Terms. J Prosthet Dent 2005;94:10-92.

2. Rahn AO, Heartwell CM. Syllabus of Complete Dentures $4^{\text {th }}$ ed. Philadelphia, PA, Lea and Febiger; 1986. p. 441-85.

3. Raczka TC, Esposito SJ. The "Jiffy" denture: A simple solution to a sometimes difficult problem. Compend Contin Educ Dent 1995;16:916-8.

4. Pound E. An all-inclusive denture technic. J Am Dent Assoc 1963;67:16-22.

5. Soni A. Trial anterior artificial tooth arrangement for an immediate denture patient: A clinical report. J Prosthet Dent 2000;3:260-3.

6. Zarb GA, Bolender CL, Hickey JC, Carlsson GE. Boucher's Prosthodontic Treatment for Edentulous Patients. $10^{\text {th }}$ ed. St. Louis: MO, Mosby; 1990. p. 534-60.

7. Jivanescu A, Marcauteanu C, Bratu D. Immediate complete denture: A case report. TMJ 2003;53:293-6.

8. Bouma LO, Mansueto MA, Koeppen RG. A nontraditional technique for obtaining optimal esthetics for an immediate denture: A clinical report. J Prosthod 2001;10:97-101.

9. Kralevic S, Panduric J, Badel T, Celic R. Immediate complete denture. Acta Stomotol Croat 2001;35:281-5. 